\title{
Imunoidentificação de Albumina e Osteopontina no Plasma Seminal de Reprodutores Taurinos e Zebuínos
}

\section{Imunoidentification of Albumin and Osteopontin in Seminal Plasma of Taurine and Zebuine Bulls}

\author{
Eneder Rosana Oberst ${ }^{*}$; Maria Inês M. Jobim ${ }^{1} ;$ Helena Iturvides Cimarosti²; \\ Diogo Onofre Souza ${ }^{3}$; Christianne Gazzana Salbego 3 ; \\ Vera Beatriz Wald ${ }^{4}$; Rodrigo Costa Mattos ${ }^{4}$
}

\begin{abstract}
Resumo
As proteínas do plasma seminal de 14 reprodutores ( 7 Bos taurus taurus e 7 Bos taurus indicus), foram analisadas por eletroforese bidimensional, em géis de poliacrilamida a $8 \%$, corados por Comassie Blue. Três bandas protéicas, presentes em $100 \%$ das amostras de plasma seminal, foram quantificadas de acordo com a densidade óptica exibida: $195 \mathrm{kDa}$, pI 6,5-7,5; $66 \mathrm{kDa}$, pI 5,4 e $55 \mathrm{kDa}$, pI 4,5. As amostras de plasma seminal provenientes de taurinos apresentaram densidades ópticas significativamente superiores $(\mathrm{p}<0,05)$ às dos zebuínos na banda de $55 \mathrm{kDa}$, que foi imunoidentificada como osteopontina. As demais proteínas analisadas não apresentaram variações significativas entre as subespécies. A banda protéica de $66 \mathrm{kDa}$, foi imunoidentificada como albumina. Nas amostras provenientes de taurinos, as densidades ópticas das três bandas protéicas quantificadas não evidenciaram variação significativa entre os reprodutores. Entretanto, nos zebuínos, as densidades ópticas da albumina apresentaram diferenças significativas entre os touros $(\mathrm{p}<0,05)$.
\end{abstract}

Palavras-chave: bovinos, plasma seminal, proteínas, eletroforese bidimensional.

\begin{abstract}
Two dimensional polyacrylamide gel electrophoresis was performed in seminal plasma of seven Bos taurus taurus and seven Bos taurus indicus bulls with high semen freezability, from an artificial insemination center. In a 8\% polyacrylamide gels, three bands of 195, 66 and $55 \mathrm{kDa}$, present in 100\% of the samples in both sub-species, were analyzed by their optical densities. In Bos taurus samples, the opticals densities of $55 \mathrm{kDa}$ band, imunoidentified as osteopontin were superior $(\mathrm{p}<0.05)$ than Bos indicus samples. The $66 \mathrm{kDa}$ band was imunoidentified as albumin. In the Bos taurus samples, the bands did not show any variation among the bull samples, but in the Bos indicus, the albumin optical densities showed significant variation among samples.
\end{abstract}

Key Words: Bovines, Seminal Plasma Proteins, Bidimensional Electrophoresis.

\footnotetext{
1 Doutor, Dep. Patologia Clínica Veterinária, Faculdade de Veterinária, Universidade Federal do Rio Grande do Sul, E-mail: oberst@vortex.ufrgs.br

2 Mestre, Dep. Bioquímica, Instituto de Ciências Básicas da Saúde, UFRGS.

3 Doutor, Dep. Bioquímica, Instituto de Ciências Básicas da Saúde, UFRGS.

4 Doutor, Dep. Medicina Animal, Faculdade de Veterinária, UFRGS. Trabalho realizado no Laboratório de Inseminação Artificial da Faculdade de Veterinária e Dep. Bioquímica, Instituto de Ciências Básicas da Saúde da UFRGS-RS.

* Autor para correspondência.
} 


\section{Introdução}

A técnica de eletroforese vem sendo utilizada para identificação e mapeamento dos componentes do plasma seminal em bovinos desde a década de 50 (LARSON; SALISBURY, 1954). Os primeiros trabalhos utilizaram eletroforese em papel, gel de agar, gel de amido, acetato de celulose (SZUMOWSKI, 1956). Mais recentemente, tem-se utilizado eletroforese uni ou bidimensional em gel de poliacrilamida (MANJUNATH et al., 1987; KILLIAN et al., 1993; BRANDON et al.,1999). Vários componentes protéicos do plasma seminal foram relacionados com os índices de fertilidade de reprodutores bovinos (KILLIAN et al., 1993), suínos (FLOWERS, 1998) e eqüinos (BRANDON et al., 1999) e com a congelabilidade (RONCOLETTA, 1999; RONCOLETTA et al., 1997, 1999, 2000) e a viabilidade do sêmen (AL SOMAI et al.,1994; BARRIOS et al., 2000). As diferenças na composição do plasma seminal entre taurinos e zebuínos, verificadas por meio de eletroforese unidimensional, referem-se às variações na proteína total e à presença ou à ausência de determinadas bandas protéicas (ROCHA et al., 1974; MARTINS JÚNIOR et al., 1995; RONCOLETTA, 1999; RONCOLETTA et al., 1997, 1999).

O presente trabalho teve como objetivo analisar as proteínas de alto peso molecular presentes em $100 \%$ das amostras do plasma seminal de reprodutores de alta congelabilidade de sêmen, taurinos e zebuínos, por meio de eletroforese bidimensional.

\section{Material e Métodos}

Foram utilizados 14 reprodutores adultos, doadores de sêmen de uma central de inseminação artificial. Sete eram taurinos, sendo dois da raça Holandesa, cinco da raça Red Angus e os demais, zebuínos da raça Nelore. Os animais apresentavam índice superior a $90 \%$ de ejaculados viáveis pósdescongelação do sêmen, com valores superiores aos critérios mínimos exigidos pelo Colégio Brasileiro de Reprodução Animal (1998), sendo considerados, de acordo com os critérios da central, como animais de alta congelabilidade do sêmen. A taxa de congelabilidade foi baseado em um total de 2.296 congelações realizadas.

O sêmen foi coletado por vagina artificial e uma alíquota de 1,0 mL foi centrifugada por 20 minutos a $1.500 \mathrm{x}$ g, para a obtenção do plasma seminal, congeladas em nitrogênio líquido e posteriormente recentrifugadas por 60 minutos a $10.000 \mathrm{x}$ g, divididas em alíquotas, congeladas e mantidas a $-70{ }^{\circ} \mathrm{C}$. A determinação das proteínas totais foi realizada de acordo com Lowry et al., (1951) e a eletroforese bidimensional conforme o descrito por O'Farrel et al. (1977), modificado por Rodnight et al. (1988).

A primeira dimensão (NEPHGE) consistiu em uma focalização isoelétrica em gradiente de $\mathrm{pH}$ não equilibrado, em gel tubular $(10 \mathrm{~cm}$ de comprimento e $1 \mathrm{~mm}$ de diâmetro) de poliacrilamida a 3,5\%, com gradiente de $\mathrm{pH} 2-10$. Foi aplicada a quantidade de $200 \mu \mathrm{g}$ de proteína nos géis, e a corrida eletroforética, com duração de 90 minutos, foi realizada com $800 \mathrm{~V}$ de voltagem, corrente de $10 \mathrm{~mA}$ e potência de 0,125 W por tubo. Após a corrida, os géis foram mantidos em $-20^{\circ} \mathrm{C}$ até serem transferidos para a segunda dimensão. Esta se consistiu de uma eletroforese em placas $(16 \mathrm{~cm} \times 14 \mathrm{~cm})$ de gel (SDS-PAGE) a $8 \%$, onde as proteínas previamente separadas pela carga elétrica migraram conforme seu peso molecular. A corrida de segunda dimensão teve a duração de 6,5 horas, e iniciava com voltagem máxima fixada de 125 $\mathrm{V}$ e corrente de $20 \mathrm{~mA}$ por placa. Como marcador de peso molecular foi utilizado $10 \mu 1$ do padrão SDS $6 \mathrm{H}^{1}$ (de pesos moleculares entre 29 e $205 \mathrm{kDa}$ ).

Os géis foram corados em solução de Azul de Comassie $^{2}$ (Comassie Brilliant Blue 250-R 0,15\%; ácido acético $3 \%$; metanol ${ }^{4} 53 \%$ ) por aproximadamente 18 horas. A descoloração foi realizada, durante cerca de 4 horas, em solução fixadora (ácido acético 7\% e metanol 53\%), sob agitação, com substituição da solução a cada hora. Ao término desta etapa, a solução de fixação foi substituída pela solução 
de secagem, composta de glicerol ${ }^{5} 1 \%$ e metanol $50 \%$. Os géis foram mantidos nesta solução por $2 \mathrm{~h}$ sob agitação e, a seguir, colocados para secar entre duas folhas de papel celofane, sobre uma placa de vidro.

Depois de secos, os géis foram escaneados (Scanjet $6100 \mathrm{C}^{6}$ ) e analisados para a determinação da densidade óptica das bandas protéicas, expressa em pixeis e quantificada em percentagem relativa ao total do gel, utilizando o programa OptiQuant Acquisition \& Analysis ${ }^{7}$. Foram realizadas várias reaplicações da mesma amostra, para a obtenção de pelo menos dois géis bidimensionais de excelente qualidade, a fim de se excluir quaisquer possíveis variações na utilização da técnica.

Foram quantificadas três proteínas, identificadas como 2527 e 29. Estas bandas protéicas foram quantificadas porque apresentaram menor variabilidade nas amostras de plasma seminal de todos os animais, recebendo inicialmente a denominação de pontos âncora. As demais bandas presentes nos géis não foram quantificadas em razão da grande variabilidade que apresentaram entre todas as amostras dos reprodutores.

As bandas protéicas 27, de $66 \mathrm{kDa}$, pI 5,4 e 29, de $55 \mathrm{kDa}$, pI 4,5 foram imunoidentificadas por western blotting. As proteínas foram transferidas dos géis para membrana de nitrocelulose ${ }^{8}$, conforme descrito por Towbin et al. (1979). Para imunodetecção da banda de $55 \mathrm{kDa}$, a membrana foi bloqueada com solução de MTBS (leite em pó desnatado $5 \% 9 \mathrm{em}$ tampão TBS, Tris $^{10} 20$ mM, NaCl ${ }^{11} 500$ mM, pH 7,5). Para imuno-detecção da banda de $66 \mathrm{kDa}$, a membrana foi bloqueada com PVP- $40^{12}$. Após o bloqueio, as membranas foram incubadas com os anticorpos específicos (anti-osteopontina policlonal 1:1000, anti-albumina monoclonal $\left.{ }^{13} 1: 800\right)$. Os anticorpos secundários utilizados foram anti-IgG de coelho ${ }^{14}$ para a banda de $55 \mathrm{kDa}$ e anti-IgG de camundongo ${ }^{15}$ para a banda de $66 \mathrm{kDa}$, biotinilados conjugados à peroxidase e estreptoavidina e diluídos a 1:3000 em MTBS. Para identificação da reação, utilizou-se o método do luminol ${ }^{16}$, onde a peroxidase reage com o reagente de luminol e emite luminescência, que sensibiliza o filme de raio- $\mathrm{X}^{13}$.

O delineamento experimental foi completamente casualizado, em um fatorial hierárquico, sendo considerado um dos fatores a sub-espécie e outro fator os touros dentro da sub-espécie. Os logaritmos das percentagens relativas das bandas protéicas foram comparados entre as sub-espécies por análise de variância (teste F). Como teste complementar foi utilizado o teste de Tukey, usando-se o nível de significância de 5\%. O programa estatístico utilizado foi o SAS (Statistical Analysis System), versão 6.12, PROC GLM.

\section{Resultados e Discussão}

Os valores médios observados na dosagem de proteína total realizada nas amostras de plasma seminal dos reprodutores não diferiram estatisticamente entre as sub-espécies, sendo de $75,96 \mathrm{mg} / \mathrm{ml} \pm$ 17,67 para os taurinos e de $75,16 \mathrm{mg} / \mathrm{ml} \pm 19,54$ para os zebuínos. Os resultados situam-se dentro dos referidos por Pangawkar et al. (1988), Nauc e Manjunath (2000), diferindo do referido por Roncoletta (1999), que encontrou variações significativas na concentração de proteínas totais; em zebuínos $(71 \mathrm{mg} / \mathrm{ml} \pm 9,56)$ e taurinos $(57,30 \pm 11,76)$ de alta congelabilidade do sêmen. Esta diferença pode ter ocorrido pelo fato do referido autor ter realizado a coleta das amostras em vários períodos durante o ano, o que poderia ter evidenciado flutuações na concentração protéica do plasma seminal.

Em razão da grande variabilidade observada nas bandas protéicas com pesos acima de $40 \mathrm{kDa}$, nas amostras de ambas as sub-espécies, foram quantificadas apenas três proteínas, presentes em $100 \%$ das amostras analisadas. As bandas analisadas foram identificadas como 25 (195 kDa, pI 6,57,5), 27 (66 kDa, pI 5,4) e 29 (55 kDa, pI 4,5), conforme se verifica na Figura 1. A análise de outras bandas de não foi realizada, em razão da grande variabilidade entre todas a mostras dos animais, con- 
forme o referido por Frazer et al. (1996), Roncoletta et al. (1977) e Roncoletta et al. (1999).

A Tabela 1 apresenta os pesos moleculares e pI aproximados das bandas protéicas de alto peso molecular, médias e desvio padrão das densidades ópticas das bandas observadas em 18 géis bidimensionais de amostras de plasma seminal de sete reprodutores taurinos e em 17 géis de amostras de sete zebuínos de alta congelabilidade do sêmen, e valores de p entre as espécies e entre os reprodutores.

Verifica-se, pela Tabela 1, que as três proteínas quantificadas, aquelas presentes em $100 \%$ das amostras, conforma já referido anteriormente, apresentaram pesos moleculares entre 55 e $195 \mathrm{kDa}$ e pI entre 4,5 a 7,5, com densidade óptica média de 1,22 a 2,13. A banda 29 foi imunoidentificada como osteopontina, utilizando-se o anticorpo policlonal específico, que não reagiu com nenhuma outra banda protéica presente na amostra avaliada (Figura 3). Na comparação entre sub-espécies, foi a única banda que apresentou diferença significativa $(p<0,05)$, ocorrendo maior densidade óptica na amostras de reprodutores taurinos em relação às amostras dos zebuínos. A osteopontina é uma glicoproteína ácida, isolada da matriz óssea bovina, cartilagens, pele fetal, cérebro, rins, ovário, útero, bem como da urina, bile e leite bovinos (Kerr et al., 1991; Sorensen; Petersen, 1993). Esta proteína foi localizada nas ampolas e vesículas seminais, mas não foi detectada no testículo, epidídimo, canal deferente, próstata e glândula bulbo uretrais, indicando que a proteína não se ligaria ao espermatozóide, ou teria apenas uma associação transitória com a membrana espermática (CANCEL et al.,1999). Em reprodutores taurinos, Killian et al. (1993), observaram que esta proteína seria um dos marcadores de alta fertilidade existentes no plasma seminal. No entanto, Cancel et al. (1999), consideraram que a relação entre osteopontina no plasma seminal e a fertilidade em machos seria indireta, pela proteção a infecções bacterianas (Brow et al., 1992) que a proteína proporcionaria na superfície das glândulas acessórias, determinando então um efeito positivo na fertilidade. a congelabilidade do sêmen. Jobim et al. (2002) verificaram que esta proteína apresentou densidades ópticas significativamente superiores nas amostras de plasma seminal de reprodutores de alta congelabilidade de sêmen, independentemente da subespécie a que pertenciam. Entretanto, quando se compararam amostras de plasma seminal de taurinos e zebuínos de alta congelabilidade de sêmen, como no presente trabalho, as amostras de taurinos apresentaram as maiores densidades ópticas. Em sua maioria, os trabalhos que identificaram e relacionaram esta proteína foram realizados em raças taurinas, e na literatura consultada, não há relatos de quantificação da osteopontina no plasma seminal de zebuínos.

A banda $27(66 \mathrm{kDa}, \mathrm{pI} 5,4)$ foi imunoidentificada como albumina, utilizando-se o anticorpo monoclonal específico, que não reagiu com nenhuma outra banda protéica presente na amostra avaliada (Figura 2). Não foram observadas variações significativas nas densidades ópticas desta banda, entre as amostras de taurinos e zebuínos. As variações na concentração de albumina seminal foram associadas em geral, com alterações na espermiogênese (SZUMOSKI, 1956) e hipoplasia testicular (ROCHA, 1974) e os reprodutores utilizados no presente experimento eram animais sadios, em regime regular de coleta e comercialização de sêmen. Nas amostras de zebuínos, ocorreram variações individuais significativas nas densidades ópticas desta banda, fato não observado nas de taurinos, que apresentaram maior homogeneidade na expressão da proteína. Roncoletta et al. (1997) e Roncoletta (1999), também observaram maior homogeneidade no perfil protéico do plasma seminal nas amostras de plasma seminal de reprodutores taurinos do que nas amostras de zebuínos. Este resultado foi atribuído à seleção genética que a sub-espécie taurina vem sendo submetida ao longo do tempo.

A banda 25 (195 kDa, pI 6,5-7,5) poderia ser considerada como globulina, tendo em vista que estas proteínas são referidas no plasma sangüíneo com semelhantes pesos moleculares.

Recentemente, a osteopontina foi relacionada com 
Concluindo, pela análise eletroforética albumina do plasma seminal de reprodutores taurinos bidimensional das proteínas de alto peso molecular de amostras de plasma seminal de reprodutores de alta congelabilidade de sêmen, das sub-espécies taurina e zebuína, verificou-se que existe ampla variação nas proteínas de pesos moleculares acima de $40 \mathrm{kDa}$, em ambas as espécies. Das três bandas protéicas analisadas, foram imunoidentificadas a e zebuínos apresentaram uniformidade de expressão entre as espécies. As concentrações de osteopontina, entretanto, foram superiores $(\mathrm{p}<0,05)$ nas amostras de plasma seminal dos animais da sub-espécie taurina. Tendo em vista que os reprodutores eram considerados como de alta congelabilidade do sêmen, as variações observadas podem também reflealbumina e a osteopontina. As concentrações de tir padrões específicos de cada sub-espécie.

Tabela 1 - Bandas protéicas analisadas, pesos moleculares $(\mathrm{kDa})$ e pontos isoelétricos $(\mathrm{pI})$ aproximados, média (\%) e desvio padrão das densidades ópticas das proteínas de alto peso molecular observadas em 18 géis bidimensionais de amostras de plasma seminal de sete reprodutores taurinos e em 17 géis de amostras de sete zebuínos de alta congelabilidade do sêmen, e valores de p entre as sub-espécies e entre os reprodutores.

\begin{tabular}{|c|c|c|c|c|c|c|c|c|c|}
\hline \multirow{3}{*}{$\begin{array}{c}\text { Banda } \\
\text { Protéica }\end{array}$} & \multirow{3}{*}{$\begin{array}{c}\text { Peso } \\
\text { Molecular } \\
\mathrm{kDa}\end{array}$} & \multirow{3}{*}{$\mathrm{pI}$} & \multirow{2}{*}{\multicolumn{3}{|c|}{$\begin{array}{c}\text { Taurinos } \\
\mathrm{n}=7\end{array}$}} & \multirow{2}{*}{\multicolumn{3}{|c|}{$\begin{array}{c}\text { Zebuínos } \\
n=7\end{array}$}} & \multirow{3}{*}{$\mathrm{p}^{* *}$} \\
\hline & & & & & & & & & \\
\hline & & & Média & Desvio & $\mathrm{p}^{*}$ & Média & Desvio & $\mathrm{p}^{*}$ & \\
\hline 25 & 195 & $6,5-7,5$ & 1,39 & $\pm 0,23$ & 0,506 & 1,45 & $\pm 0,33$ & 0,082 & 0,97 \\
\hline 27 & 66 & 5,4 & 2,02 & $\pm 0,28$ & 0,963 & 2,13 & $\pm 0,58$ & 0,001 & 0,56 \\
\hline 29 & 55 & 4,5 & 1,59 & $\pm 0,50$ & 0,491 & 1,22 & $\pm 0,18$ & 0,740 & 0,02 \\
\hline
\end{tabular}

* Valor da probabilidade do teste de comparação entre reprodutores

** Valor da probabilidade do teste de comparação entre sub-espécies

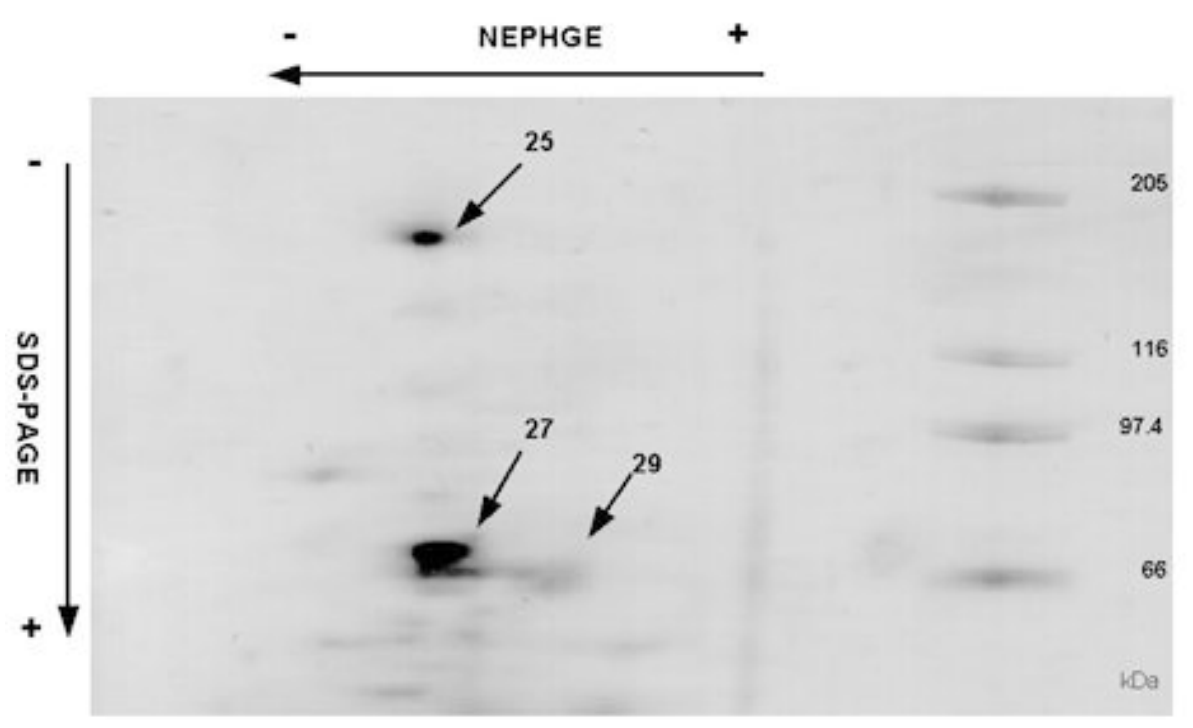

Figura 1 - Proteínas de alto peso molecular do plasma seminal bovino. Gel SDS-PAGE a 8\%, corado por azul de Comassie. A seta superior indica a direção do gradiente de $\mathrm{pH}$ não equilibrado (NEPHGE), na primeira dimensão. Os marcadores de peso molecular e respectivos pesos estão colocados à direita do gel. 


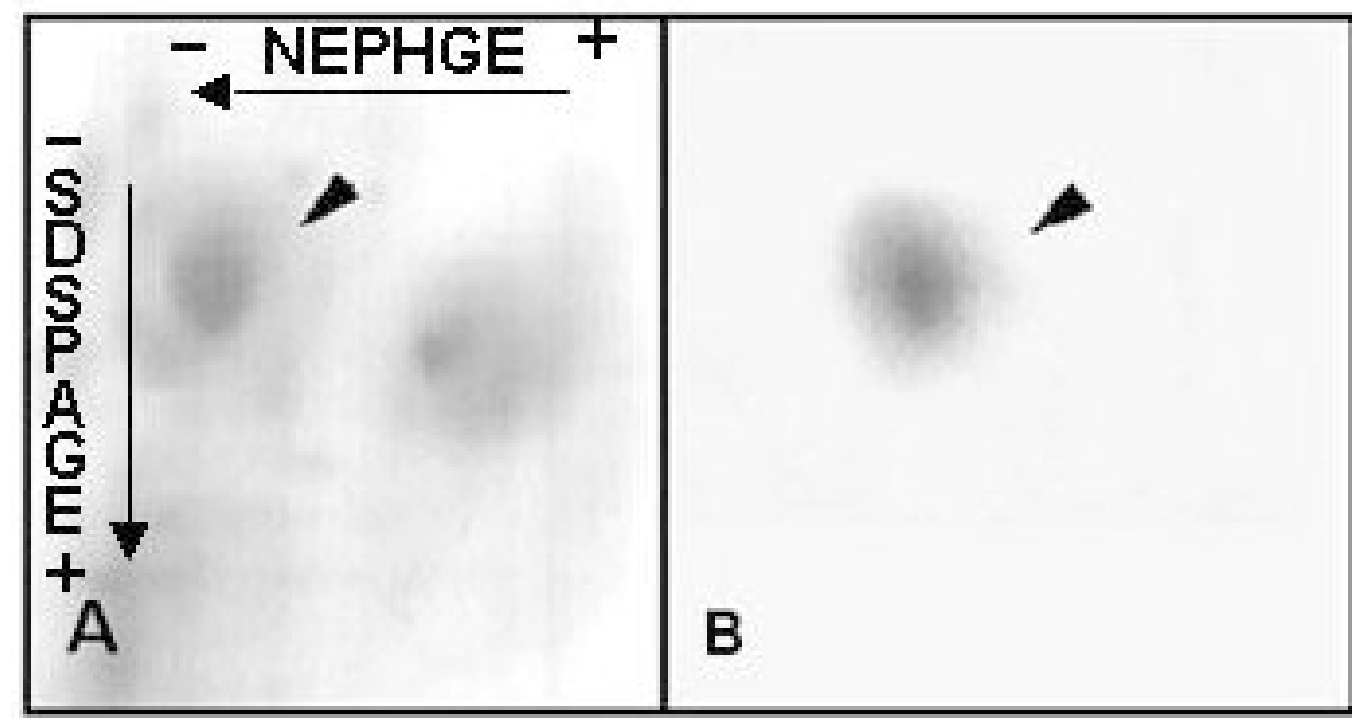

Figura 2 - Imunoidentificação da albumina no plasma seminal bovino. Em A, a seta indica a posição da proteína no gel de poliacrilamida corado por azul de Comassie. Em B, autoradiografia, mostrando a imunodetecção com anticorpo monoclonal anti-antialbumina.

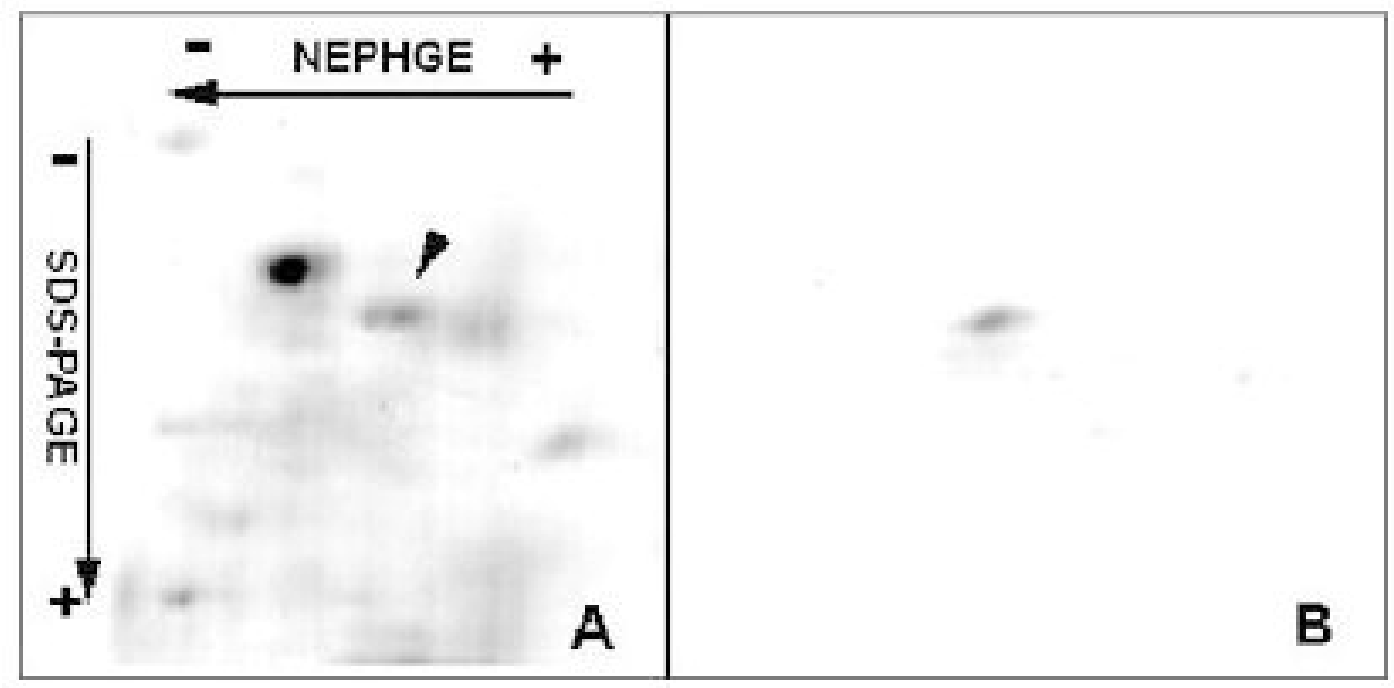

Figura 3 - Imunoidentificação de osteopontina no plasma seminal bovino. Em A, a seta indica a posição da proteína no gel corado por azul de Comassie. Em B, autoradiografia, mostrando a imunodetecção com anticorpo policlonal anti-osteopontina. 


\section{Agradecimentos}

Os autores agradecem à Empresa Lagoa da Serra SA, pelo fornecimento das amostras e financiamento parcial, ao Dr. Gary Killian do J.O. Almquist Center- Pennsylvania State University-EUA, pelo anticorpo anti-osteopontina e à FAPERGS (Fundação de Amparo à Pesquisa do Rio Grande do Sul), pelo financiamento do experimento.

\section{Fontes de Aquisição}

${ }^{1}$ Sigma; ${ }^{2}$ Comassie Blue, Amersham Pharmacia Biotech do Brasil; ${ }^{3,4}{ }^{5}$ Synth; ${ }^{6}$ Hewlett Packard; ${ }^{7}$ Packard Instruments, versão 02.00; ${ }^{8}$ Hybond ECL, Amersham Pharmacia Biotech do Brasil; ${ }^{9}$ Molico, Nestlé; ${ }^{10}$ Tris, Amersham Pharmacia Biotech do Brasil; ${ }^{11} \mathrm{NaCl}$, Synth; ${ }^{12} \mathrm{PVP} 40$, Sigma; ${ }^{13} \mathrm{~B} 2901$, Sigma; ${ }^{14}$ PATCH 17353, Amersham Pharmacia Biotech do Brasil; ${ }^{15}$ PATCH 150714, Amersham Pharmacia Biotech do Brasil; ${ }^{16}$ Amersham Pharmacia Biotech do Brasil; ${ }^{17}$ Omat, Kodak

\section{Referências}

AL-SOMAI, N.; VISHWANATH, R.; SHANNON, P. et al. Low molecular weight components in bovine semen diffusate and their effects on motility of bull sperm. Reproduction Fertility and Development, Melbourne, v.6, p.165-171,1994.

ASHWORTH, P.J.C., HARRISON, R. A. P.; MILLER, N.G.A. et al Survival of ram spermatozoa at high dilution: protective effect of simple constituents of culture media as compared with seminal plasma. Reproduction Fertility and Development, Melbourne, v.6, p.173-180, 1994.

BARRIOS, B.; PEREZ-PE, R.; GALLEGO, M. et al. Seminal plasma proteins revert the cold-shock damage on ram sperm membrane. Biology of Reproduction, Champaign, v.63, n.5, p.1531-1537, 2000.

BRANDON, C.I.; HEUSNER, G.L.; CAUDLE, A.B. et al. Two-dimensional polyacrylamide gel electrophoresis of equine seminal plasma proteins and their correlation with fertility. Theriogenology, Stoneham, v.52, p.863873,1999 .

BROWN, L.F.; BERSE, B.; VAN DE WATER, L., et al. Expression and distribution of osteopontin in human tissues: widespread association with luminal epithelial surfaces. Molecullar Biology Cellullar, Coimbra, v.3, p.1169-1180, 1992.

CANCEL, A.M.; CHAPMAN, D.A., KILLIAN, G.J. Osteopontin localization in the holstein bull reproductive tract. Biology of Reproduction, Champaign, v.60, p.454460, 1999.

COLÉGIO BRASILEIRO DE REPRODUÇÃO ANIMAL. Manual para exame andrológico e avaliação de sêmen animal. 2.ed. Belo Horizonte: CBRA, 1998.

FLOWERS, W. L. Boar fertility and artificial insemination. In: INTERNATIONAL PIG VETERINARY SOCIETY CONGRESS, 15., 1998, Birmingham. Proceedings... Birmingham: International Pig Veterinary Society, 1998. p.45-52.

JOBIM, M. I. M.; OBERST, E. R.; SALBEGO, C. G. et al. Albumina e osteopontina - Proteínas do plasma seminal bovino relacionadas com a congelabilidade do sêmen. Revista Brasileira Reprodução Animal, Belo Horizonte, v.26,n.4, p.296-305, 2002.

KERR, J.M.; FISHER, L.W.; TERMINE, J.D. et al. The cDNA clonig and RNA distribuition of bovine osteopontin. Gene, Amsterdam, v.108, p.237-243, 1991.

KILLIAN, G. J.; CHAPMAN, D. A., ROGOWSKI, L. A. Fertility-associated proteins in Holstein bulls seminal plasma. Biology of Reproduction, Champaign, v.49, p.1202-1207, 1993.

LARSEN, L. B. ; RAVN, P.; BOISEN, A. et al. Primary structure of EPV20, a secretory glycoprotein containing a previously uncharacterized type of domain. European Journal Biochemical, v.15, n.243, p.437-441, 1997.

LARSON, B. L.; SALISBURY, G.W. The proteins of bovine seminal plasma I. Preliminary and electrophoretics studies. Journal Biology Chemistry, v.206, n.2, p.741-749, 1954.

LOWRY, O H.; ROSEBROUGH, W. J.; FARR, A. L. et al. Protein measurement with folin phenol reagent. Journal Biology Chemistry, v.193, p.265-275, 1951.

MANJUNATH, P.; SAIRAM, M.R., UMA, J. Purification of four gelatin-binding proteins from bovine seminal plasma by affinity chromatography. Bioscience Reproduction, v.7, n.3, p.231-238, 1987.

MARTINS JÚNIOR, A.; RAMOS, P.R.R.; SILVA, R.L. Perfil eletroforético das proteínas do plasma seminal de touros de origem européia e zebuína. In: CONGRESSO BRASILEIRO REPRODUÇÃO ANIMAL, 11, 1995, Belo Horizonte. Anais.... Belo Horizonte: Colégio Brasileiro de Reprodução Animal, 1995. p.272. 
NAUC, V.; MANJUNATH, P. Radioimmunoassay for bull seminal plasma proteins (BSP-A1/A2, BSP-A3, and BSP30 kilodaltons), and their quantification in seminal plasma and sperm. Biology of Reproduction, Champaign, v.63, p.1058-1066, 2000.

O'FARREL, P. Z.; GOODMAN, H.M.; O'FARREL, P. $\mathrm{H}$. High resolution of wo-dimensional electrophoresis of basic as well as acidic proteins. Cell, Cambridge, v.12, p.1133-1142, 1977.

PANGAWAKAR, G.R.; SHARMA, R.D., SINGH, R. Protein, sialic acid and zinc concentrationin the seminal plasma of bulls in relation to freeability of semen. Indian Veterinary Journal, Madras, v.65, p.58-60,1988.

ROCHA, M. C.; GARCIA, O. S., FERREIRA NETO, J.M. et al. Proteína total e seu fracionamento eletroforético em plasma seminal de touros zebus com alterações reprodutivas. Arquivos da Escola de Veterinária da Universidade Federal de Minas Gerais, Belo Horizonte, v.26, n.2, p.223-233, 1974.

RODNIGHT, R.; ZAMANI, R., TWEEDALE, A. An investigation of the experimental conditions for studying phosphorylation in micro-slices of rat brain by twodimensional electrophoresis. Journal of Neuroscience Methods, Amsterdam, v.24, p.27-48, 1988.

RONCOLETTA, M.; FRANCHESCHINI, P. H.; de LIMA et al. Perfil em SDS-PAGE das proteínas do plasma seminal e sua relação com a congelabilidade do sêmen de touros zebuínos. Ars Veterinária, Jaboticabal, v.13, n.2, p.135-140, 1997.

RONCOLETTA, M. Perfil em SDS-PAGE das proteínas de espermatozóides e plasma seminal relacionados com a congelabilidade de sêmen de touros., 1999. 109p. Dissertação (Mestrado em Ciências Agrárias e Veterinárias) - Faculdade de Ciências Agrárias e Veterinárias, Universidade Estadual Paulista, Jaboticabal-SP, 1999.

RONCOLETTA, M.; FRANCHESCHINI, P. H.; de LIMA, V. F. M. H. et al. Perfil em SDS-PAGE das proteínas do plasma seminal e sua relação com a congelabilidade do sêmen de touros doadores da raça Gir. Brazilian Journal of Veterinary Research and Animal Science, São Paulo, v.36, n.2, 1999. Disponível em: <http:/ /www.scielo.br>. Acesso em: abr. 2002.

RONCOLETTA, M.; MORANI, E.S.C. ; FRANCHESCHINI, P. H. et al. Caracterização da proteína $26 \mathrm{KDa}$ do plasma seminal e sua relação com a congelabilidade do sêmen de touros. Arquivos Faculdade Veterinária UFRGS, Porto Alegre, v.28, n.1, p.323, 2000.

SORENSEN, E. S., PETERSEN, T. E. Purification and characterization of three proteins isolated from the proteose peptone fraction of bovine milk. Journal of Dairy Research, Cambridge, v.60, p.189-197, 1993.

SZUMOWSKI, P. Quelques rèsultats de l' examen éclectrophorétique des protéines du plasma seminal de taureau. In: INTERNATIONAL CONGRESS OF ANIMAL REPRODUCTION, 3., 1956, Cambridge. Proceedings.... Cambridge, 1956. p.37-42.

TOWBIN, H.; STAEHELIN, T.; GORDON, J. Electroforetic transfer of proteins from polyacrilamide gels to nitrocellulose sheets: Procedures and some applications. Processes Academic Science, v.76, p.43504354, 1979. 